\section{Design of a typical residence for the elderly in Morocco}

\author{
M. Bouaoudate, ${ }^{\mathbf{1}}$ Jaouad El Harti, ${ }^{1}$ \\ M. Maamar, ${ }^{2}$ R. Abouqal ${ }^{3}$ \\ ${ }^{1}$ Laboratory of Medicinal Chemistry \\ and Hospital Pharmacy, Faculty of \\ Medicine and Pharmacy, University \\ Mohamed V, Rabat; ${ }^{2}$ Internal Medicine \\ Service and ${ }^{3}$ Acute Medical Unit, \\ University Hospital Ibn Sina, Rabat, \\ Morocco
}

\begin{abstract}
The population of Moroccan elders is in full increase; their requirements for quality and quantity of services are becoming increasingly important. On the basis of this, reality and extension of many major innovative projects in Morocco (industrial expansion plan, renewable energy stations, the road infrastructure network, rural electrification, drinking water, accelerated urbanization, globalization...) gain importance. Reflection on the design of a typical residence for the elderly has become an ambitious idea possessing all the chances of its success; it is also worth noting that it is a citizen opportunity to be seized by all political decision-makers for the promotion of health and the improvement of the quality of life of a growing category of the population. The typical residence of the elderly remains not only a place of life but also an environment of therapeutic care and at different levels of autonomy and dependence of our elders.
\end{abstract}

\section{Introduction}

The aging cannot be dissociated from the demographic transition since it is undoubtedly its product. In recent years, the aging population has become a major concern of stakeholders in the field of health and sociology; Global demographic trends indicate that the number of older people ( 65 and over) will increase. ${ }^{1,2}$ According to the High Commission for Planning in its national report on population policy, Morocco is one of the countries where the evolution started later, but where it seems to have to accelerate at a significantly faster pace. Hence the need to take the necessary measures in time: Admittedly, the proportion of elderly people (aged 60 years and over) increased only slightly, from $7 \%$ to $8 \%$ between 1960 and 2004, a level lower than those of particularly aged countries such as France (22\%) and Japan (22\%). ${ }^{3-5}$

A slow evolution in relative terms should not obscure the extent of aging in absolute terms. By less than one million in 1960 , the number of elderly people rose to 2.4 million in 2004. According to the projections of the High Commission for Planning (HCP), they would become 5.8 million in 2030. Operating at an average annual rate of $3.5 \%$, compared to $0.9 \%$ for the entire population during the same period, the elderly would account for $15.4 \%$ of the total population by 2030 , twice the current level.

The urban housing of large modern cities does not express the need for multigenerational cohabitation and does not respond to it automatically; the urban contraction of housing reflects the birth of a nuclear family. ${ }^{6}$ To remain together or to find ourselves together seems to us at the moment as situations which do not correspond to individual desires and aspirations, Rather has interests and group choices, family in this case;

In Morocco, elderly people are housed almost entirely in ordinary houses and in the same situation as younger households, whereas this category of the population has these specific needs and it has very specific requirements influenced by the regression and the physiological reduction of these functional capacities requiring consideration of compatible normative measures in terms of safety displacement and comfort.

However, in France, the ambition of adapting housing and urban planning to the management of the elderly is one of these major concerns, for the lagging of a comprehensive global strategy that is still far behind other countries (Japan, Germany) that have already and long ago introduced into their policies the anticipation of the phenomenon of this disturbing demographic situation of aging.

Broussy $^{7}$ cited in his report the adaptation of the population to the aging of its population: It was during the opening session of the XVIII World Congress of Gerontology and Geriatrics in Rio de Janeiro (Brazil), in June 2005, the project Cities-Friendly of the Elders was developed, and in 2006, the first collaborating cities in Vancouver, the Vancouver protocol, under the supervision of the organization World Health Organization, then applied in 33 cities in the world.

Benchmarking successful experiences can give a boost to developing good practices and improving a way of doing things in an ever-changing Moroccan context; And why not encourage the migration of seniors to the typical residence of the elderly if the services have become attractive and similar
Correspondence: Jaouad El Harti, Laboratory of Medicinal Chemistry and Hospital Pharmacy, Faculty of Medicine and Pharmacy, University Mohamed V, Rabat, Morocco. Tel: +212.661480985 .

E-mail : harti.jaouad@gmail.com

Key words: elderly, typical residence, audit.

Contributions: $\mathrm{MB}$ and JEL designed the study, data collection, analysis, interpretation and manuscript preparation; $\mathrm{MM}$ and RA, interpretation, manuscript revision and approval.

Conflict of interest: The authors declare that no conflict of interest is associated with this work.

Funding: none

Received for publication: 20 December 2017. Revision received: 5 June 2018.

Accepted for publication: 5 July 2018.

This work is licensed under a Creative Commons Attribution NonCommercial 4.0 License (CC BY-NC 4.0).

(C) Copyright M. Bouaoudate et al., 2018 Licensee PAGEPress, Italy

Journal of Public Health in Africa 2018; 9:835 doi:10.4081/jphia.2018.835

to those offered in the residences of their home countries and at reasonable prices in a country.

The important dimension of taking care of seniors in a typical residence of the elderly requires professional assistance sufficiently competent to adequately respond to the various aspects of a multidisciplinary responsibility in order to: i) assist the resident in the optimal (maximum) use of these abilities: biopsychosocial and even affective by promoting its autonomy; ii) promoting and protecting one's health as one of the institution's priorities; iii) stimulate the development of new skills and the use these skills to contribute to the diverse activities of the community.

The design of a typical residence for the elderly is a project where everything will be implemented for the well-being of the senior person in his daily life, his social life and his civic life with the advantages and constraints that he can present.

\section{Materials and Methods}

In order to better identify the problem and to target the appropriate benefits for the management of this vulnerable population 
group, the Ishikawa diagram reflects the different elements that influence the quality of life of elderly people living in a typical residence. ${ }^{8}$ In fact for the good design of a typical residence for the elderly, it is necessary to consider the following elements: Workforce or people: all that is linked to a human action (personal, users, suppliers, management...); Method: everything related to the organization (procedure, operating procedures, regulations, processes...); Equipment: all that requires an investment (machines, installations, vehicles, appliances...); Middle: all that is external to the effect and on which it is a priori difficult to act; Material: everything that is consumable (water, gas, electricity, paper, raw materials that can be ideas, information...).

An audit was conducted at some residences for the elderly in the Rabat region. A questionnaire has been developed taking into account the elements mentioned above according to the Ishikawa diagram.

\section{Results}

Of all the residences visited, three of them can be considered as typical residences; the others are only guest houses. Thus, audit results of these residences typical of elderly have been reported.

\section{«Do you have admission guides?»}

The admission guide; and the booklet of reception at the residence must be minutely established; the three residences have admission guides and booklets that help to understand the living conditions and the rules of procedure of these establishments.

\section{"Compliance with law 14-05?"}

The articles of law 14-05 concerning the conditions for the opening and management of social welfare institutions are to be taken into consideration, in addition to the implementation of the manuals of the procedures of the charters; Compliance with existing regulations would be one of the major priorities of the typical residence of the elderly.

Law 14-05 on the conditions of opening and management of social protection institutions is to be taken into consideration, despite this; the audited institutions are categorically unfamiliar with this law.

"Are human resources sufficient and multidisciplinary to ensure the different activities of caring for the elderly?»

The allocation of competent human resources to the gerontological care of elderly people is of paramount importance, hence the need to recruit a multidisciplinary team.
It has been noted that all residences have multidisciplinary teams. Only one residence has additional specialties, namely chiropodists, speech therapists and facilitators.

Some specialties such as careers, nurses and physiotherapists are in great demand because of the need for their permanent presence and proximity to the elderly.

These residences are managed by nonprofit associations and do not have an administrative management chart. The organizational chart must be part of the basic documents to ensure optimal management of the administrative activity based on the principle of good governance.

"Are the logistics and equipment sufficient to meet the specific needs of the elderly?»

The logistics of the residence must be sufficiently supplied with all necessary supplies for the proper functioning of the institution and/or establishment; provide an efficient management system to anticipate the occurrence of any probable stock shortages or feeding.

The managers of these establishments confirmed the presence of equipment and logistics in sufficient quantities, the unforeseen disruption of stocks and supply are taken into consideration beforehand.

\section{«State of the premises»}

The premises are mostly satisfactory and allow a state of comfort for users. The signs are available in all establishments which facilitates movement. The design of the residences visited has gardens and benches for the relaxation of users.

One of these residences has the colors of soils well thought out and well adapted to the different activity spaces. Also presents a room for the reception and maintenance of psychologists.

The use of technology for surveillance and for the anticipation of certain risks remains an element of reflection for the future given the ethical implications of gerontology that it generates. ${ }^{9-13}$ We noted the presence of surveillance and vigilance cameras to ensure the careful monitoring of frail elderly people.

\section{Discussion}

The United Nations General Assembly proclaimed 1 October as the International Day for the Elderly by its Resolution 45/106 of 14 December 1990. This decision is part of UN initiatives such as the International Plan of Action on Aging, adopted in 1982 by the World Assembly on Aging and approved by the General Assembly the same year.

In Morocco, the policy of old age is a recent creation, and the denomination itself appears in April 2002, in the national report on aging by the Minister of Employment, Vocational Training, Social Development of Solidarity. ${ }^{14}$

The National Strategy for the Elderly (2009) by the Ministry of Social Development, Family and Solidarity marks a date in the evolution of ideas and in the awareness of the various problems posed by the junction of demographic aging and allowed the dissemination of the term old age policy. Undeniable efforts have been made by the involvement and the different sectors and actors to fight against precariousness and social exclusion, to empower the elderly and to develop health centers for their care.

Many social welfare institutions have been established, but age dimensions are not taken into account; the elderly are placed in the same places with other persons with a disability or homeless.

In addition, the housewives who were in charge of keeping the children and the elderly returned to the world of work now, the children are entrusted to the nursery and preschools while the elders are left to their wise with all the risks - to make their movements in case of urgent or needy need. The negative effects of residential isolation in the absence of caregivers (family, relatives, neighbors who are sensitive to responding to emergency calls), greatly affect their overall health to an increasingly serious deterioration difficult to repair.

In 2008, on the occasion of the World Day of Older Persons, the High Commission for Planning (HCP) presented the results of the national survey on the elderly in Morocco. The study shows the weak role played by social institutions, even though the population of Morocco tends to age.

The middle class is continuously looking for a solution to these elders to leave them in the right hands surrounded by a secure system and a special intention, to anticipate the installation of the psychological complications of aging, namely: folds on oneself; mistrust; isolation and short solitude of a mental and physical pathological phenomenon by giving them the opportunity to break away from isolation; to maintain a sense of usefulness and to diminish the sense of disability; to improve their quality of life and the opening to the other of the workshops of animations will allow them the maintenance of physical and motor activity. 
Thinking of such an institution gives rise to an in-depth reflection on a systemic approach to which the means to be put in place to meet qualitatively and quantitatively the expectations of a population with specific needs that of frail elderly persons in a process is a technical method based on fundamental social engineering.

The medicalization of the residence is strongly recommended considering the fragile and vulnerable state of its elderly clientele; the contribution of health professionals from different specialists is always sought to respond to and respond to requests for general and gerontological care. ${ }^{6}$ It should not be denied that $1 / 4$ of people aged 60 and over live with at least four pathologies, so they are poly pathologically polymedic and in front of their gerontophobia they can become drug-dependent, with their drug consumption and non-compliance with Treatment of adverse events (drug toxicity, intolerance, dizziness and falls, etc.); For this reason the place of the pharmacist clinician for the orientation and the re-evaluation of prescriptions is unavoidable within the residences of the ages.

This conception refers us to a steering committee endowed with a rewarding and ambitious strategy to ensure an environment of happiness and well-being for our elders; and an experienced team for administrative management.

Multiple meetings will be organized, including the idea of design thinking to harmonize the construction of premises with the specificity of the population to be taken over and the perpetuation of the establishment.

The assignment of health professionals to ensure the activities of maintaining and improving the autonomy of our seniors: occupational therapists; physiotherapists; psychomotor agents; hygienists; geriatricians; psychologists; rheumatologists; dieticians; the animators; and other external stakeholders deemed useful for the proper functioning of the residence; for specific medical care conventions can be developed and implemented. Without forgetting the trades: carpentry; masonry; Ironwork; plumbing; electricity; gardening.

Continuing education for practitioners will be a common denominator of correct quality care for the elderly through: participation in colloquiums; congresses; seminars; the organization of scientific days and open houses will make the elderly residence a research and training institution.

The permanent consultation of the jurists remains an essential assistance for the fulfillment of its noble mission of taking care of the elders in the rules of the art.
Like other institutions, the residence of the elderly in the course of all these activities must ensure the application of the regulations in force; the establishment and updating of procedures and management manuals is a key to the success of such a project; the establishment of good administrative governance inevitably involves drawing up job descriptions in consultation with all the stakeholders, actors and health professionals; the organizational chart for the development of the hierarchy and division of tasks and of paramount importance must be established and made available to the staff of the institution in this sense. ${ }^{15} \mathrm{An}$ introduction to the pragmatics that the organizational chart is part of the internal documents that must be mandatory in certain places and adds that within the framework of a rigorous administrative organization; there is a job description for each profession regularly updated according to the laws and regulations in force.

A training unit specialized in gerontology in the vicinity of senior residents must be available to harmonize training with their care and develop this emerging discipline in our country; This unit can also contribute to the supervision of students and trainees of the different institutions wishing to work in gerontology in the framework of a convention.

An equipment allowing the realization of a geriatric care should be put in place with a biomedical team to ensure preventive and curative maintenance: Light vehicles; Sports equipment; the lifts ; Rehabilitation and rehabilitation apparatus; Channels with sound system; The institution may grant a mini bus for organized outings; Excursions and residents' trips to attend special events.

Some safety devices may be installed in the elderly's apartments to facilitate their movement and avoid accidents. For example, handles adjacent to baths, showers, lavatories, solid ramps to stairs; Adequate lighting at the top and bottom of the steps, anti-slip mats in front of the bathtub and kitchen sink, non-slip rubber strips in the shower and bathtub, Good housekeeping also helps to reduce the possibility of accidents. ${ }^{16}$

Responding to the needs and expectations of seniors in social services vary greatly between different age groups and also between men and women, not to mention that chronological age is not necessarily related to the individual's potential; it is time to believe that the majority of the elderly can be in good health and want to stay active in their daily lives.

In the same way, the richness of the range provided to our seniors in various activities contributes enormously to the reduction of their dependence and to the increase of their autonomy as they are carried out through therapeutic workshops: therapeutic garden; therapeutic arts; music therapy; zootherapy; cooking therapy; psychotherapy; the residence is a place of creation, of invention to rebuild itself.

Through the Internet networks, residents can communicate with their families; their friends; it is the visit of their relatives is difficult for the reason of the distance; to watch movies according to the personal desire of each one of them.

\section{Conclusions}

The design of a typical elderly residence is part of our contribution to the great collective social project in a gerontological environment aimed at improving the quality of life of our elders and it is only through the collaboration that we will age harmoniously together as pointed out by Dominique de Pasquale.

\section{References}

1. Korotayev A, Goldstone JA, Zinkina J. Phases of global demographic transition correlate with phases of the Great Divergence and Great Convergence. Technol Forecast Soc Change 2015;95:163-9.

2. Attanasio O, Kitao S, Violante GL. Global demographic trends and social security reform. J Monetary Econ 2007;54:144-98

3. Pablo D, Nejm B. Multi-agentive transformations of rural livelihoods in mountain ICCAs: The case of the decline of community-based management of natural resources in the Mesioui agdals (Morocco). Quatern Int 2017;437:16575.

4. Tu Chi N, Matthias R. CommunityDriven Development and Social Capital: Evidence from Morocco. World Dev 2017;91:28-52.

5. Mendonça RM, Engler RC, Vitolo F, Oliveira VG. Working for the Elderly About Getting to Know Their Needs. Procedia Manufacturing 2015;3:614652

6. Royaume Du Maroc, HautCommissariat Au Plan. Enquête nationale sur les personnes agées. 2006. Available from : http:/www.social-protection.org/gimi/RessourceDownload.a ction?ressource.ressourceId=14058.

7. Broussy L. Adaptation de la société au vieillissement de sa population. 2013. Available from : https://www.ladocu- 
mentationfrancaise.fr/var/storage/rapports-publics/134000173.pdf

8. Hui ECM, Wong FKW, Chung KW, Lau KY. Housing affordability, preferences and expectations of elderly with government intervention. Habitat Int 2014;43:11-21.

9. Axisa F, Ditmar A, Delhomme G. Smart clothes for the monitoring in real time and conditions of physiological, emotional and sensorial reaction of human. In: 12th Annual Int. Conf. BME, Piscataway: IEEE Proceedings 2003; 297-300
10. Ditmar A, Delhomme G, Axisa F. Les capteurs biomédicaux pour la télésurveillance. In: Colloque esanté Lille 02. Lille: CERIM. 2002

11. Ditmar A, Delhomme G, Axisa F, Gehin C. New concepts and technologies in home care and ambulatory monitoring. Stud Health Technol Inform 2004;108: 9-35

12. Noury N. A smart sensor for the remote follow up of activity and fall detection of the elderly. In: Microtechnologies in Medicine and Billogy 2nd Annual Int. Conf. BME, Piscataway: IEEE
Proceedings, 314-317. 2002.

13. Coturier P, Franco A, Buguet A. Body actimetry to warn of pressure sores. Lancet 1996;347:627.

14. Jacquet I. La vieillesse au Maroc. Les éditions belges Academia-Bruylant; 2009

15. Garric N., Calas F. Introduction à la pragmatique. Paris: Edditions Hachette; 2007.

16. Birchenall J, Steight ME. Soins aux personnes âgées. Paris: Renouveau pédagogique; 1977. 